\title{
Empirical Research on the Impact of FDI to Environmental Pollution in Jiangsu \\ Wenjing Shan
}

${ }^{1}$ School of Economics, Shanghai University, Shanghai, China

a1551073147@qq.com

*The corresponding author

Keywords: Jiangsu province; FDI; Environmental pollution; Empirical research

\begin{abstract}
The paper collect the data of industrial waste water, industrial waste gas, industrial solid wastes, foreign direct investment (FDI) and net export of Jiangsu Province from 1995 to 2014 ,with the methods of econometrics and E-views, to analyze quantitatively the relationship between FDI of Jiangsu and environment. The conclusion is industrial waste has no correlation between FDI. But industrial waste and industrial solid waste have a positive correlation between them and FDI, and the correlation coefficients were 0.89 and 0.47 . FDI is not the Granger cause for industrial waste water, but for industrial waste gas and industrial solid wastes. Generally, Jiangsu FDI has a negative influence in environment, and the Hypothesis of Pollution Haven is proofed.
\end{abstract}

\section{江苏省 FDI 对环境影响的实证研究 \\ 单文晶 \\ 1. 上海大学经济学院、人口、资源与环境经济学, 中国上海 200444 \\ a1551073147@qq.com}

摘要：本文以江苏省 1995 年至 2014 年的工业废气、工业废水和工业固体废弃物的排放量, 以及外商直接投资（FDI）金额和净出口数额为基础，实证分析了江苏省 FDI 与环境的关系， 得出江苏省 FDI 与工业废水相关性不大, 与工业废气和工业固体废弃物相关性较大, 相关系 数分别为 0.89 和 0.47 ; FDI 不是工业废水的格兰杰原因, 是工业废气和工业固体废弃物的格 兰杰原因。总体来说，江苏 FDI 对环境存在负面影响，污染避难所假说成立。

关键词：江苏省； FDI；环境影响；实证研究

\section{1. 前言}

江苏省依托其独特的地理位置, 在吸引外资方面显示出极大的吸引力, 引进数额一直持续增 加。2003 年, 江苏省首次超越广东省成为全国吸引外资最多的省份。2012 年, 江苏省合同利 用 FDI 项目为 4156 个, 合同 FDI 为 571 亿美元, 实际利用 FDI 为 357 亿美元, 占全国吸引 FDI 的 $32 \%$ 。而随着经济开放程度的加大, 江苏地区持续出现的水污染、大气污染和耕地污染 等一系列环境污染问题也引发了人们的深思, 尤其是 2013 年江苏大部分地区爆发了为期数月 的雾皬天气，给人们生活带来不便，也迫使人们思考如何实现对环境的保护和有效利用。在 此背景下, 本文以江苏省为例, 尝试探讨外国直接投资（FDI）是否会对环境产生影响, 是正 面影响还是负面影响, 以及相关性的大小。

通过查阅发现, 鲜有文献在江苏省省级层面上对 FDI 与环境影响进行分析考证, 因此本文通 过分析 FDI 与江苏省环境质量的关系，揭示 FDI 的环境效应，为探讨 FDI 与中国生态环境协 调发展，解决跨境环境污染转移问题，促进中国又好又快发展提供有益参考。 


\section{2. 文献综述}

\section{1. 国外文献综述}

国外学者关于 FDI 与环境污染的分析并没有达成一致观点。由于 FDI 对发达国家和发展中国 家的环境影响不相同, 环境影响评估存在困难, 而且影响环境质量的因素也有很多, 因此在 FDI 对环境影响方面很难达成一致意见。但是对于 FDI 对投资所在地环境污染的影响理论一 般有三个方面。

第一种观点认为 FDI 对环境存在负面影响。Walter 和 Ugelow(1979) ［1］最早提出“污染天 堂假说”。Baumol 和 Oates（1984）在理论方面对“污染天堂假说”进行了全面系统的阐述。第 二种观点认为 FDI 对环境存在正面影响。Letchumanan,R.与 Kodama,F (2000) [2] 研究认为, FDI 不仅有益于一国的技术进步, 而且通过引进环境友好型技术和产品从而提高一国的环境 福利。另外 Eskeland 与 Harrison (2002) [3] 的研究发现, 投资污染密集型产业的外资企业 比国内企业更重视环境保护，会采用环境友好型的生产技术，投入更多治污设备。第三种观 点认为 FDI 对东道国既有正面影响又有负面影响。Keydiche Stevens(1993)和 Runge(1994), 从 规模效应、结构效应、技术效益三个维度分析了 FDI 对东道的环境的影响, 指出规模效应会 加剧环境退化，而结构效应、技术效益会使促进环境改善。Borregaard,N 和 Dufey,A.（2002） 以智利和秘鲁为例, 研究了 FDI 对东道国环境的影响, 认为技术效应和政策效应对环境具有 正向作用，而规模效应具有负面作用。

2.2. 国内研究现状

随着 FDI 在我国投资规模的增加以及环境污染的弊端逐渐显现, 我国学者于 1995 年第三次全 国工业普查时期开始研究 FDI 与环境之间的相互作用。不过, 国内学者普遍认为, FDI 对我 国的环境质量产生了消极的影响。

夏友富（1999）［4］对中国污染密集型产业进行了详细划分与阐述, 通过分析 FDI 企业在国 内污染密集型企业中的比重, 得出 FDI 对环境影响具有很强的负面作用的结论。赵细康(2003)

[5] 认为, 从国家层面上来说, FDI 并没有表现出明显的污染转移趋势, 但是如果从产业部 门的角度分析, 则会发现外商在纺织印染业、电镀业、制造业以及火力发电业等几大污染较 严重的边际产业的投入规模已远远超过了我过所有产业部门 FDI 的平均规模, 从而严重的破 坏了我国的生态环境。兰天（2004） [6] 认为, 贸易自由化能够吸引更多的 FDI , 但是由此 引发的对环境的污染也会加剧。何洁（2006）[7] 利用中国 29 省市的面板数据研究了中国 FDI 与工业 SO2 排放量之间的关系, 结果表明 FDI 股本每增加 1\%, 工业 SO2 排放增加 0.098\%。 FDI 对经济增长和结构转换引起的污染排放增加, 抵消了 FDI 对环境管制影响引起的污染减 少。这是对“污染天堂”假说的理论解释。张彦博和郭亚军 (2009) [8] 通过分析 FDI 在我国 产生的环境效应, 认为我国 FDI 存量的增加导致的经济规模扩张和经济结构的重污染化加剧 了污染排放，而技术效应带来了正面的环境效应。王珏和李哲（2011）［9］对陕西省 FDI 的 环境效应进行了实证分析, 发现 FDI 有导致陕西省污染指标上升的趋势, 且 FDI 与环境污染 指标之间呈 U 型关系。阚大学（2014）［10］运用 Meta 方法定量分析 FDI 对中国环境污染的 影响, 得出 FDI 显著加剧了环境污染, 但这种效应呈下降趋势, 以至于 2000 年后 FDI 改善 了环境质量。

\section{3. 模型建立与数据选取}

虽然影响江苏省环境变化的因素很多, 但是本文主要研究的是由 FDI 引起的环境变化, 所以 本文忽略了对环境影响较小的其他指标。因此建立的模型初步定为:

LnEnv $=\alpha+\beta_{0}$ Lnfdi $+\beta_{1} \operatorname{Lnnx}+\varepsilon$

Eq.1 中, LnEvn 代表污染物排放量, 包括工业废水排放量 (Lnwater)、工业废气排放量 (Lngas) 和工业废弃固体物排放量（Lnsolid）；FDI 代表实际外商直接投资金； pu 代表净出口；water 代表工业废水排放量、gas 代表工业废气排放量、solid 代表工业固体废弃物排放量; Ln 是取 
对数值, $\alpha$ 表示截距, $\beta_{0} 、 \beta_{1}$ 表示变量系数, $\varepsilon$ 表示随机扰动项。文章选取了 1995 年--2014 年江苏省实际利用 FDI, 全省工业废水排放量（water）、工业废气排放量（gas）、工业固体废 弃物（solid）排放量和净出口（nx），数据均来源于各年的《江苏省统计年鉴》。

\section{4. 实证分析}

4. 1. 相关性检验

对已建模型进行估计, 得出以下结果, 如表1所示。由表1看出, 回归结果FDI与污染物排放量 的相关关系体现在相关系数 $\beta_{0}$ 上。工业废气和工业固体废弃物与FDI在 $1 \%$ 的显著水平上均显 著为正, FDI每增加 $1 \%$, 工业废气和工业固体废弃物分别增加 $0.89 \%$ 和 $0.47 \%$ 。工业废水的 $\mathrm{t}$ 值较小，没有通过检验，说明两者之间相关性不大。

表 1 方程估计结果

\begin{tabular}{llll}
\hline & 工业废水 & 工业废气 & 工业固体废弃物 \\
\hline$\alpha$ & 11.87 & -2.66 & 2.57 \\
$\beta_{0}$ & 0.065 & 0.89 & 0.47 \\
& $(0.83)$ & $(5.55) * * *$ & $(4.48) * * *$ \\
$\beta_{1}$ & -0.03 & -0.01 & 0.10 \\
& $(-0.72)$ & $(-0.12)$ & $(1.80) *$ \\
R-squared & 0.33 & 0.90 & 0.93 \\
\hline
\end{tabular}

注：括号中的是相对应的 $\mathrm{t}$ 值; ***、**、*分别代表 $1 \% 、 5 \% 、 10 \%$ 的显著性水平。

\section{2. 单位根检验}

在建立模型之前, 我们要对各序列进行单位根检验, 采用的方法是ADF检验法, 滞后期根据 AIC准则来确定。我们设定实际输入的原序列为Lnfdi、Lnwater、Lngas、和Lnsolid, 它们对 应的一阶差分序列为D（Lnfdi）、D（Lnwater）、D（Lngas）和D（Lnsolid），得到表2。

表 $2 \mathrm{ADF}$ 检验结果

\begin{tabular}{llllll}
\hline 检验类型 & ADF值 & $1 \%$ 临界值 & $5 \%$ 临界值 & $10 \%$ 临界值 & 是否平稳 \\
\hline Lnfdi & -0.25 & -3.89 & -3.05 & -2.67 & 否 \\
D (Lnfdi) & -4.60 & -3.96 & -3.08 & -2.68 & 是 \\
Lnwater & -2.45 & -3.89 & -3.05 & -2.67 & 否 \\
D (Lnwater) & -3.86 & -3.96 & -3.08 & -2.68 & 是 \\
Lngas & -3.35 & -4.62 & -3.71 & -3.30 & 否 \\
D (Lngas) & -5.94 & -3.92 & -3.07 & -2.67 & 是 \\
Lnsolid & -3.15 & -4.62 & -3.71 & -3.30 & 否 \\
D (Lnsolid) & -6.17 & -3.92 & -3.07 & -2.67 & 是 \\
\hline
\end{tabular}

由ADF检验结果可知, 序列Lnfdi、Lnwater、Lngas、和Lnsolid都是非平稳序列, 它们的一阶 差分数列是平稳数列, 表示为D（Lnfdi） I (1)、D（Lnwater） I (1)、D（Lngas） I (1) 和D（Lnsolid） I （1）。可见，D（Lnfdi）、D（Lnwater）、D（Lngas）和D（Lnsolid）都 是一阶单整数列, 它们相互之间有可能存在协整关系。

4.3. 协整检验

本文对 1995 年 2014 年江苏 FDI 对工业三废排放量的协整关系进行检验，分别对 Lnwater、 Lngas、Lnsolid 和 LnFDI 进行最小二乘估计, 得出回归方程估计残差序列, 对残差序列 e 做 
单位根检验，如果其残差是平稳的，则两个变量之间存在稳定的协整关系。分别对三个回归 方程的残差进行检验，选择无截项距、无趋向距的 ADF 检验。如表 3 所示。

表 3 FDI 与工业三废之间的协整检验

\begin{tabular}{llllll}
\hline ADF检验对象 & t-Statistic & P值 & 各水平下临界值 & 结果是否平稳 \\
\hline FDI 与废水的残差 & -2.49 & 0.33 & $10 \%$ level -3.29 & 否 \\
FDI与废气的残差 & -3.76 & 0.0009 & $1 \%$ level & -2.71 & 是 \\
FDI与固废的残差 & -4.00 & 0.0005 & $1 \%$ level & -2.71 & 是 \\
\hline
\end{tabular}

检验结果表明，工业废水与 FDI 回归方程的残差在任何显著性水平上均不平稳，工业废气和 工业固体废弃物与 FDI 的回归方程的残差在 $1 \%$ 的显著性水平上平稳。因此表明江苏工业废 气和固体废弃物的排放量与 FDI 之间存在长期的均衡关系, 而工业废水与 FDI 不存在长期均 衡关系。

4. 4. 格兰杰因果检验

对 FDI、工业废水、工业废气和工业固体废弃物做格兰杰检验, 结果如表 4, 取 5\%作为显著 性水平，滞后期为 1 。通过格兰杰因果检验发现，工业废水、废气和固体废弃物是

FDI 变动的格兰杰原因, FDI 是工业废气和工业固体废弃物变动的格兰杰原因, 而不是工业 废水的格兰杰原因。

表4 FDI与工业废水、废气和固体废弃物的格兰杰因果检验

\begin{tabular}{lcccr}
\hline \multicolumn{1}{c}{ Null Hypothesis: } & Obs & F-Statistic & Prob. & 检验结果 \\
\hline LNWATER does not Granger Cause LNFDI & 17 & 10.649 & 0.0057 & 拒绝 \\
LNFDI does not Granger Cause LNWATER & & 0.124 & 0.7300 & 接受 \\
LNGAS does not Granger Cause LNFDI & \multirow{2}{*}{17} & 7.309 & 0.0171 & 拒绝 \\
LNFDI does not Granger Cause LNGAS & & 7.095 & 0.0185 & 拒绝 \\
LNSOLID does not Granger Cause LNFDI & \multirow{2}{*}{17} & 5.343 & 0.0365 & 拒绝 \\
LNFDI does not Granger Cause LNSOLID & & 13.681 & 0.0024 & 拒绝 \\
\hline
\end{tabular}

\section{5. 结果与讨论}

从江苏省 FDI 与环境的因果关系和趋势关系的研究中可知: 江苏 FDI 对环境产生了负面影响。 通过对 FDI 与工业“三废”的因果关系分析, 发现 FDI 与工业废水在相关性检验中没有通过检 验, 两者相关性不大, 但与工业废气和工业固体废弃物呈正相关, 且关系显著, FDI 每增加 $1 \%$ ，两者分别增加 $0.89 \% 、 0.47 \%$ ，即更多的 FDI 会使工业污染物排放增加，对环境造成更 多的破坏; 通过协整检验发现 FDI 与工业废气、工业固体废弃物均存在着长期稳定的协整关 系; 进行格兰杰检验后得出：工业三废是 FDI 的格兰杰原因, FDI 是工业废气和废气固体物 的格兰杰原因，而不是工业废水变动的格兰杰原因。

工业废水与 FDI 没有相关性, 原因可能有两方面, 一方面是近年来国家调整产业结构, 优化 产业升级, 增加引入通用设备、计算机和电气机械等外资企业的比例, 产生废水较多的食品、 纺织加工产业却在 FDI 中所占比例较小; 另一方面, 国家“节能减排”政策的严格实施有效改 善了企业的生产行为, 使得工业废水的排放量逐年减少。工业废气和固体废弃物排放量与 FDI 有显著相关性，FDI 每增加 1\%，两者分别增加 $0.89 \% 、 0.47 \%$ 。重工业在产业投资中依旧占 有较高比例, FDI 越多, 废气和废渣排放量越多, 且相关系数显著, 说明在引进和输出外商 投资的过程中, 会对当地遗留大量废渣, 对环境造成较大破坏, 验证了污染天堂假说, 因此 引进外资时不仅要考虑 GDP 的增长，同时要考虑有利于保护环境的环境友好型优质“资本”。 


\section{参考文献}

[1] Walter, I. and J. Ugelow. Environment policies in development countries. [J].World Bank Discussion Paper, 1997

[2] Letchumanan, Kodama, Reconciling conflict between the "pollution-haven" hypothesis and an emerging trajectory of international technology transfe[J].Research,2000,29(1); 59-79

[3] Eskeland, Harrison .Moving to greener pasture Multinationals and the Pollution-heaven hypothesis. National Bureau of Economic Research Working Paper on No.8888,2012,(4)

[4] 夏友富.外商投资中国污染密集型产业现状、后果及其对策研究 [J].管理世界1999，(3): 109 123

[5] 赵细康.环境保护与产业国际竞争力----理论与实证分析[M]. 北京: 社会科学出版社, 2003: 319 361

[6] 兰天，贸易与跨国界环境污染[M].北京：经济管理出版社，2004:211 286

[7] Jie He. Pollution haven hypothesis and environment impacts of foreign direct investment: The case of industrial emission of sulfur dioxide (SO2) in Chinese provinces. Economics 2006:228-245

[8] 张彦博, 郭亚军.FDI的环境效应与我国引进外资的环境保护政策[J].中国人口、资源与环 境，2009.19(4): 7-12

[9] 王珏，李哲.陕西省FDI的环境效应分析[J].国际贸易问题，2011，(11)：126-137

[10] 阚大学.FDI对中国环境污染影响的实证研究[J].环境科学研究，2014，27(1): 106-112

\section{References}

[1] Walter, I. and J. Ugelow. Environment policies in development countries.[J].World Bank Discussion Paper, 1997

[2] Letchumanan, Kodama, Reconciling conflict between the "pollution-haven" hypothesis and an emerging trajectory of international technology transfe [J].Research,2000,29(1); 59-79

[3] Eskeland, Harrison .Moving to greener pasture Multinationals and the Pollution-heaven hypothesis. National Bureau of Economic Research Working Paper on No.8888,2012,(4)

[4] Youfu Xia .Foreign investment in China's pollution intensive industry present situation, the consequences and countermeasures research[J].Management World, 1999,(3):109 123

[5] Xikang Zhao. Envirmental Protectand industries' international competition[M].Beijing, Social science press, 2003:319 361

[6] Tian Lan, Trade and cross-border pollution of the environment. Beijing, Economics Management Press, 2004:211 286

[7] Jie He. Pollution haven hypothesis and environment impacts of foreign direct investment: The case of industrial emission of sulfur dioxide (SO2) in Chinese provinces. Economics 2006:228-245

[8] Yanbo Zhang, Yajun Guo. The environmental effect of FDI and the introduction of foreign investment in China's environmental protection policy[J].China's Population, Resources and Environment, 2009.19(4):7-12

[9] Yu Wang, Zhe Li. Environmental effect analysis of Shanxi province. International Trade Issue.[J].2011,(11):126-137

[10]Daxue Kan. Empirical Research on the Impact of FDI to Environmental Pollution in China.[J].Environment Science Research, 2014,27(1):106-112 